\title{
Quality of care provided to newborns by nursing personnel at BP Koirala Institute of Health Sciences
}

\section{Shrestha $\mathbf{M}^{1}$, Singh $\mathbf{R}^{2}$, Upreti $\mathrm{D}^{3}$}

${ }^{1}$ Associate Professor and HOD, Department of Maternal Health Nursing, ${ }^{2}$ Professor and Rector, ${ }^{3}$ Additional Professor and HOD, Department of Obstetrics and Gynaecology, BP Koirala Institute of Health Sciences, Dharan, Nepal.

\begin{abstract}
Background: Birth is a major challenge for the newborn to negotiate successfully from intrauterine to extra uterine life. The first few hours since birth is the most crucial period in the life of an infant for further growth and development, which is largely determined by the quality of care that the newborn receives.

Objective: The aim of this study is to assess the quality of care provided by nursing personnel to newborn in the labour room.

Materials and methods: This study was conducted in BP Koirala Institute of Health Science. Cross sectional, non participatory observational research design was adopted for the study. Care provided by nursing personnel to 814 normal newborns was observed. Samples were chosen by non probability purposive sampling technique. Data was collected through observational method by trained nursing personnel, using 46 items pre-tested, validated and self developed observational checklist. Care provided to newborns was observed from birth to two hours and categorised as good, average and poor based on scores obtained. Data was entered and analysed using SPSS-10. Descriptive statistics[Mean, percentage, frequencies and standard deviation] was used to describe the quality of care provided to the newborn babies.

Results: Overall quality of care was good in $42.36 \%$, average in $57.64 \%$ and none of them received poor care. Overall mean score for quality of care was 34.75/46 (75.54 \%). Regarding subscales quality of care was good in majority of newborns in areas such as Preparation to receive the baby (76.1\%), Initiation of breathing (100\%), Maintaining thermoregulation (77.3\%), Physical assessment (90.9\%), and other aspects of care (95.2\%). However the quality of care was poor in majority of newborns in establishment of breast feeding $(58.23 \%)$ and average in prevention of infection $(76.9 \%)$.
\end{abstract}

Conclusion: Study findings highlight the need for focus in establishment of breast feeding and prevention of infection.

Key words: Quality of care, newborns, nursing personnel, breast feeding, prevention of infection and assessment of newborn.

$\mathrm{T}^{\mathrm{T}}$ he health of a nation is the wealth of the nation. Today's children are tomorrow's adults. Among the life span of the childhood period neonatal period is very crucial, which to large extent determines the overall health status of the child and in turn adult life. Birth is a major challenge to the newborn to negotiate successfully from intrauterine to extra uterine life. Delivery and the first few hours of life are critical period for the further growth and development of the infant. Newborn baby is considered to be tiny and powerless, completely dependent on others for life. Within one minute of birth the normal newborn adapts from a dependent fetal existence to an independent one; capable of breathing and carrying on life process. Thus these first hours are crucial because multiple organ systems are making the transition from intrauterine to extra uterine functions ${ }^{1}$.
According to WHO report (1998) ${ }^{2}$ the global birth rate is 27.3 per 1,000 populations. In Nepal crude birth rate is 34 per 1000 and 13 death occurs in 100 live birth ${ }^{3}$ Two third of all deaths in first year occurs in the neonatal period. Over half occurs in the first hour after birth ${ }^{1,4}$. In India it is reported that $50-60 \%$ of all neonatal deaths occur within the first month of life. Of these, more than half may die during the first week of life. The risk of death is greatest during the first 24 hours of birth. Most of the deaths are due to birth asphyxia, hypothermia and infection which are preventable if the quality of care is maintained ${ }^{5}$. Worldwide about eight newborn babies

Correspondence

Mangala Shrestha

Associate Professor, Department of maternal health Nursing BPKIHS, Dharan

E-mail: mangala2003@yahoo.com 
die every minute ${ }^{6}$. Every year more than four million babies die during first week of life due to inadequate care $^{7}$. Further reduction of newborn mortality can be accomplished by improving the quality of care provided to newborn babies.

The events during the first few minutes and hours of life have an immense bearing on the immediate and long term outcome of the newborn. The basic principle of essential and effective care of newborn babies include establishment of respiration, prevention of hypothermia, establishment of breast-feeding, prevention of infection and identification of neonates who are at risk ${ }^{5,6,8,9,10}$.

The health care professional in general and nurses in particular play a vital role to ensure that the new born has best possible beginning of life and the nurse must be aware of the potential problems and be alert to the infant's changing condition and to intervene appropriately when necessary. The nurse is the first health care provider who has direct contact with the neonate during birth. Hence nurses require the knowledge and skill to take care of the babies keeping in mind the basic principles so that many complications can be prevented. BPKIHS being a tertiary care hospital in the eastern region of Nepal strives to provide best care to the consumers including mothers and babies ensuring healthy mother and baby. However, so far no systematic assessments are made to evaluate the care that is delivered especially in the area of newborns which is very crucial part of the infant's life. Thus this study was aimed to assess the quality of care that is provided by the nurses to newborns born in BPKIHS.

\section{Materials and methods}

This study was conducted in the labour room of the maternity Unit of the B.P. Koirala Institute of Health Sciences, Dharan after the approval of the ethical and research committee of the Institution from January 2006 to December 2006. A cross sectional non participatory observational research design was chosen for this study. In B.P.KIHS approximately 250-350 normal deliveries take place each month. Care provided by nursing personnel to 814 normal newborns was observed during the period of data collection. Samples were chosen through non probability purposive sampling technique. Inclusion criteria of sample included, neonates born within 37 to 42 weeks of gestation, through vaginal delivery (including low forceps and suction cups), weighing 2.5 to $3.8 \mathrm{~kg}$, with APGAR score of 9 and 10 at 1 and 5 minutes. Exclusion criteria includes neonates with prematurity, birth asphyxia and congenital malformation and babies born to high risk mothers who had pregnancy induced hypertension, heart disease, ante-partum haemorrhage, diabetes mellitus, jaundice, anaemia, HIV, Hepatitis B and Hepatitis C positive.
The data was collected by trained nursing personnel through non participatory observational method using pre-designed, validated, pre-tested observational checklist which consisted of two parts.

Part I: It consisted of details of caregivers like qualification, designation and experience and profile of the newborns.

Part II: It was 46 items observational checklist formulated on the basis of standard intervention to be performed by the health personnel. Observational checklist consisted of different tasks that are to be performed immediately after delivery with two options Yes/No (performed / not performed). A tick mark was given under the Yes or No column depending on whether the care is provided or not.

Each observed task carried one point. Each Yes response was scored " 1 " and No response was scored " 0 ". The score percentage was calculated by adding the scores obtained for each intervention. Further it consisted of different subscales of care such as-

$\begin{array}{llr}\text { 1. } & \text { Preparation to receive the baby } & -11 \text { items } \\ \text { 2. Initiation of breathing } & -3 \text { items } \\ \text { 3. Thermoregulation } & -6 \text { items } \\ \text { 4. Assessment } & -6 \text { items } \\ \text { 5. Feeding } & -10 \text { items } \\ \text { 6. Prevention of infection } & -7 \text { items } \\ \text { 7. Other aspects of care } & -3 \text { items }\end{array}$

Total obtainable score range was $0-46$. The obtained score was converted into $\%$ and quality of care was interpreted as follows:

$\begin{array}{lr}\text { Good } & 75 \% \text { and above } \\ \text { Average } & 50-74 \% \\ \text { Poor } & <50 \%\end{array}$

Data was entered and analysed using SPSS-10. Descriptive statistics such as number, percentage, mean and standard deviation were used appropriately to determine the quality of care provided to newborn babies.

\section{Results}

Care provided by nursing personnel to 814 newborns was analysed in this study. Majority of the care providers in this study were staff nurses (95\%). Regarding overall quality of care more than half of the newborns (57.6\%) received only average quality of care.

Care provided to newborns were good in relation to the subscales like initiation of breathing (100\%), physical assessment (90.9\%), maintaining thermoregulation 
$(77.3 \%)$, and preparation to receive the baby $(76.1 \%)$ and other aspects of care (95.2\%). However it was found only average in majority of the newborns in relation to prevention of infection (76.9\%). Quality of care in relation to establishment of breast feeding was poor in more than half of the cases $(58.23 \%)$.

While considering the individual tasks, majority of the newborns received poor care in terms of washing hands and wearing gowns before receiving the baby (75.1\% and $75.6 \%$ respectively). Likewise the baby was not dried and wrapped in clean cloth $(99.8 \%)$, body temperature was not checked (99\%), mother's breast was not cleaned (64\%), baby was not kept comfortably on mother's breast (58\%) while establishing breast feeding, baby's cord was not cleaned with spirit swab $(93 \%)$.

Regarding total scores of quality of care, mean percentage was highest in initiation of breathing (100) and lowest in establishment of breast feeding $((51.80 \%)$.

Table 1: Levels of quality of care in subscales

\begin{tabular}{|c|c|c|c|}
\hline \multirow[b]{2}{*}{ Areas } & \multicolumn{3}{|c|}{ Quality of care } \\
\hline & $\begin{array}{l}\text { Good } \\
\text { f ( } \%)\end{array}$ & $\begin{array}{c}\text { Average } \\
\text { f (\%) }\end{array}$ & $\begin{array}{l}\text { Poor } \\
\text { f ( } \%)\end{array}$ \\
\hline Preparation to receive the baby & $619(76.1)$ & $190(23.4)$ & $5(0.5)$ \\
\hline Initiation of breathing & $814(100)$ & 0 & 0 \\
\hline Maintaining thermoregulation & $629(77.3)$ & $183(22.5)$ & $2(0.2)$ \\
\hline Physical assessment & $740(90.9)$ & 0 & $74(9.1)$ \\
\hline Establishment of breast feeding & $324(24.8)$ & $13(1.60)$ & $477(58.23)$ \\
\hline Prevention of infection & $48(5.9)$ & $626(76.9)$ & $140(17.1)$ \\
\hline Other aspects of care & $775(95.2)$ & $31(3.8)$ & $8(1)$ \\
\hline
\end{tabular}

Table 2: Quality of care on individual tasks

\begin{tabular}{|c|c|c|c|}
\hline SN & Tasks to be performed & $\begin{array}{c}\text { Yes } \\
\text { f }(\%)\end{array}$ & $\begin{array}{c}\text { No } \\
\text { f }(\%)\end{array}$ \\
\hline 1 & Preparation to receive the baby & & \\
\hline 1.1 & Bassinette is ready with new \& clean sheet & $811(99.6)$ & $3(0.4)$ \\
\hline 1.2 & The warmer is put on & $813(99.8)$ & $1(0.2)$ \\
\hline 1.3 & Oxygen is checked & $769(94.4)$ & $45(5.6)$ \\
\hline 1.4 & Suction is in working condition & $746(91.64)$ & $68(8.36)$ \\
\hline 1.5 & Mucus sucker is kept ready & $479(58.8)$ & $335(41.15)$ \\
\hline 1.6 & $\begin{array}{l}\text { All resuscitation equipments are available \& in working } \\
\text { condition }\end{array}$ & 771(94.7) & $43(5.3)$ \\
\hline 1.7 & Emergency drugs are available & $782(96)$ & $32(4)$ \\
\hline 1.8 & Washes hands with soap \& water to receive the baby & $203(24.9)$ & $611(75.1)$ \\
\hline 1.9 & Dries hands with clean towel & $197(24.2)$ & $617(75.8)$ \\
\hline 1.10 & Wears gown & $199(24.4)$ & $615(75.6)$ \\
\hline 1.11 & Wears gloves & $811(99.6)$ & $3(0.4)$ \\
\hline 2 & Initiation of breathing & & \\
\hline 2.1 & Sucks the mouth, pharynx \& nose. & $814(100)$ & - \\
\hline 2.2 & $\begin{array}{l}\text { Holds the baby at head low position immediately after delivery } \\
\text { (without hyper extended and hyper flexed neck of the baby). }\end{array}$ & $812(98.8)$ & $2(1.2)$ \\
\hline 2.3 & $\mathrm{O}_{2}$ is available & $813(99.9)$ & $1(0.1)$ \\
\hline 3 & Thermoregulation & & \\
\hline 3.1 & Puts off the fan at the time of delivery & $635(78)$ & $179(22)$ \\
\hline 3.2 & Receives and place the baby under radiant heat source & $812(99.8)$ & $2(0.2)$ \\
\hline
\end{tabular}

Table 2 cont. to next page ... 
Table 2 cont...

\begin{tabular}{|c|c|c|c|}
\hline 3.3 & Wipes the baby and wraps in clean cloth & $813(99.9)$ & $1(0.1)$ \\
\hline 3.4 & Covers the head with cap & $809(99.4)$ & $5(0.6)$ \\
\hline 3.5 & Checks the temperature of baby before cord care. & $2(0.2)$ & $812(98.8)$ \\
\hline 3.6 & Cord care and eye care are given under the warmer & $813(99.9)$ & $1(0.1)$ \\
\hline 4 & Assessment & & \\
\hline 4.1 & Measures the height & $760(93.3)$ & $54(6.7)$ \\
\hline 4.2 & Measures the weight. & $814(100)$ & - \\
\hline 4.3 & Checks the body temperature ( any time within $2 \mathrm{hrs}$ ) & $8(1)$ & $806(99)$ \\
\hline 4.4 & Checks for abnormality & $796(97)$ & $18(3)$ \\
\hline 4.5 & Determines the patency of anus using rectal thermometer & $801(98.4)$ & $13(1.6)$ \\
\hline 4.6 & Records the findings & $814(100)$ & - \\
\hline 5 & Feeding. & & \\
\hline 5.1 & $\begin{array}{l}\text { Asking the mother to initiate breast feeding within two hours } \\
\text { of delivery }\end{array}$ & $703(86.4)$ & $111(13.6)$ \\
\hline 5.2 & Ensures the mother has had a drink/food. & $695(85)$ & $119(15)$ \\
\hline 5.3 & Washes the hands & $648(79.6)$ & $166(20.4))$ \\
\hline 5.4 & Washes the breast of mother with soap and water & $289(35)$ & $525(65)$ \\
\hline 5.5 & Cleans the nipple & $340(41)$ & $474(59)$ \\
\hline 5.6 & Dries the breast. & $339(41.6)$ & $475(58.4)$ \\
\hline 5.7 & Place the baby on the breast in comfortable position & $340(41.8)$ & $474(58.2)$ \\
\hline 5.8 & Ensures the baby has sucked for $5-10$ minutes in each breast. & $319(39.2)$ & $495(60.8)$ \\
\hline 5.9 & Assess the baby while feeding. & $320(39.3)$ & $494(60.7)$ \\
\hline 5.10 & Burps the baby. & $222(27.3)$ & $592(72.7)$ \\
\hline 6 & Prevention of infection & & \\
\hline 6.1 & Washes the hands before handling the baby & $674(82.8)$ & $140(17.2)$ \\
\hline 6.2 & Receives the baby in clean clothes. & $811(99.6)$ & $3(0.4)$ \\
\hline 6.3 & Places the baby in clean surface & $812(99.8)$ & $2(0.2)$ \\
\hline 6.4 & Cleans the eyes with sterile cotton \& clean water. & $810(99.5)$ & $4(0.5)$ \\
\hline 6.5 & Cuts the cord with sterile scissors. & $812(99.8)$ & $2(0.2)$ \\
\hline 6.6 & Cleans the cord with spirit swabs & $53(6.5)$ & $761(93.5)$ \\
\hline 6.7 & Clamps the cord with sterile clamps. & $811(99.6)$ & $3(0.4)$ \\
\hline 7 & Other aspects of care & & \\
\hline 7.1 & Identification of sex. & $813(99.9)$ & $1(0.1)$ \\
\hline 7.2 & Ties the identification tag. & $776(95.3)$ & $38(4.7)$ \\
\hline 7.3 & Administers the injection vitamin $\mathrm{K}$. & $806(99)$ & $8(1)$ \\
\hline
\end{tabular}

Table 3: Mean score, percentage, SD \& Range of Quality of care in different subscales

\begin{tabular}{|l|c|c|c|c|}
\hline \multicolumn{1}{|c|}{ Areas } & $\begin{array}{c}\text { Obtainable } \\
\text { range(score) }\end{array}$ & Mean score (\%) & SD & $\begin{array}{c}\text { Range } \\
\text { (obtained) }\end{array}$ \\
\hline 1. Over all care & $0-46$ & $34.75(75.54)$ & 3.98 & $23-43$ \\
\hline 2. Preparation to receive the baby & $0-11$ & $8.08(73.45)$ & 1.09 & $4-11$ \\
\hline 3. Initiation of breathing & $0-3$ & $3(100)$ & 0 & $2-3$ \\
\hline 4. Maintaining thermoregulation & $0-6$ & $4.77(79.50)$ & 0.43 & $3-6$ \\
\hline 5. Physical assessment & $0-6$ & $4.91(81.83)$ & 0.32 & $3-6$ \\
\hline 6. Establishment of breast feeding & $0-10$ & $5.81(51.80)$ & 3.60 & $0-10$ \\
\hline 7. Prevention of infection & $0-7$ & $5.88(84)$ & 0.53 & $1-7$ \\
\hline 8. Other aspects of care & $0-3$ & $2.94(98)$ & 0.27 & $1-3$ \\
\hline
\end{tabular}




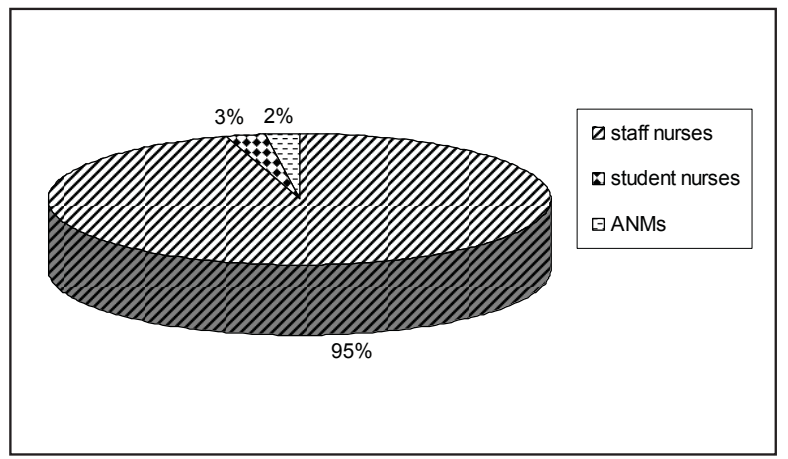

Fig 1: Distribution of care givers

\section{Discussion}

The purpose of this study was to determine the quality of care provided by the nursing personnel in the selected aspects of care to the newborn babies from birth to two hours of age in the labour room of BPKIHS, Dharan. Adaptation of newborn baby to extra uterine life to a large extent is determined by the quality of care that he or she receives immediately after birth. During the birth of a newborn and immediately after delivery, if proper measures are not taken to establish and maintain an open airway, the newborn may aspirate. Prolonged exposure, keeping wet for long time with amniotic fluid and improper drying and wrapping may result in hypothermia and metabolic problems by cold stress. Lack of proper hand washing before and after handling the baby and lack of proper aseptic techniques lead to infection and so the hospital stay will be prolonged which increases economical as well as psychological effects on the parents and hospital expenditure.

Findings of the study indicate that only $42.36 \%$ of the babies received overall good quality of care, whereas more than half of the newborns $(57.64 \%)$ received only average care. However none of the newborns received poor care. In relation to quality of care in subscales, quality of care provided in relation to receive the baby, $76 \%$ of newborns received good care and 23.4 $\%$ received average care. It was also found that tasks regarding washing and drying hands before receiving the baby was found poor for $76 \%$ of the babies. Even though almost all staff $(99.9 \%)$ were wearing the gloves only $24 \%$ staff were wearing gown before receiving the newborn babies. It may be due to shortage of gowns in labour room, while there is no shortage of gloves usually. Quality of care provided in relation to the prevention of infection was average in $76.9 \%$ and only $5.9 \%$ received good care. Even though hand washing was not done while receiving the babies in $75.1 \%$, hand washing was carried out in majority of the babies $(82.8 \%)$ while handling the babies (other than while

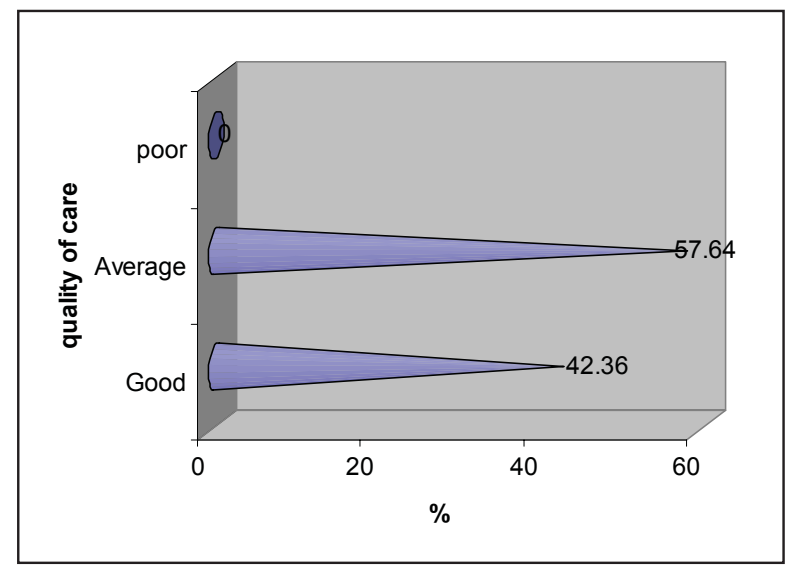

Fig 2: Levels of quality of care

receiving). Inconsistent findings in this area may be due to need for wearing gloves while receiving the baby, whereas certain other tasks can be performed with clean hands. So nurses may not be very serious about hand washing while receiving the babies with the assumption that wearing gloves is sufficient to receive the babies. It also may be due to lack of time for washing hands while the delivery is on process. Finding regarding hand washing while handling the babies in this study, quality of care is higher than the findings reported by Shakya in her study ${ }^{11}$ done in 1999 in C.M.C Hospital, India where she reported that $85 \%$ of the nurses did not wash their hands before handling the newborn babies. Improved compliance to universal precautions in this study may be due to time factor as with passage of time nurses are aware of importance of compliance to universal precautions.

Another positive finding of this study is that, quality of care was good for almost all the babies in relation to the initiation of breathing including suctioning of the mouth, pharynx and nose, holding the baby at head low position and making sure of availability of oxygen. Importance of these tasks are emphasised in the numerous literatures to prevent newborns from aspiration before the rest of body is delivered and the first breath is taken ${ }^{12,13,14}$.

The quality of care in relation to maintaining thermoregulation was found to be good in $77.3 \%$ of babies and only $0.2 \%$ of newborn babies received poor care. It was noticed that during delivery ceiling fans were kept off $(75 \%)$, almost all $(99.8 \%)$ babies were placed under the radiant heater soon after delivery. Therefore the chance of heat loss was minimal. In contrast, the care was found to be poor $(99.8 \%)$ in terms of checking body temperature after delivery which is very important aspect of nursing care. It indicates the fact that even though the appropriate measures are 
taken to prevent heat loss no efforts are made to check the actual temperature of the newborns which draws attention to emphasize the care providers to follow the protocol including checking temperature. Quality of nursing care was also poor in relation to other task such as positioning of the baby $(58.2 \%)$, burping the baby $(72.7 \%)$, and assessing the baby while feeding $(60.7 \%)$. These may be associated with many factors such as over load of nursing staff, lack of time etc. It also may be due to assumption of nurses that, these tasks can be performed later in the postnatal ward by the nurses working in the postnatal ward rather than the nurses in labour room immediately after birth. Nurses also may view that mothers will be tired immediately after delivery, thus they may ensure promoting rest rather than emphasising on breast feeding and its related tasks.

Quality of care in terms of physical assessment of newborn care was found to be good $(90 \%)$. Over all care in relation to the initiation of breast feeding soon after delivery was average (76.9\%). Informing the mother to initiate breast-feeding was found to be good $(85 \%)$. These findings are not consistent with the study findings of Malar who reported that the implementations of the Baby friendly initiative policies were poor in the maternity wards of the CMC \& Hospital, Vellore ${ }^{15}$. Invariably numerous literatures ${ }^{16,17,18,19,20}$ strongly advocate breast feeding because of its health benefits for the child as well as the mother herself, and also for the advantages of the bonding which it facilitates. These findings emphasise the need for developing protocol and checklist, which will include all-important essential newborn care.

\section{Conclusion}

This study provides the baseline data about the quality of care received by the newborns immediately after birth which will help the policy makers and health professionals to plan for strategies where the quality of care is not satisfactory. Study findings highlight the fact that quality of care was good in areas such as initiation of breathing and physical assessment, but it was poor in relation to establishment of breast feeding which underscores the need for focusing on this area, by various measures such as providing feedback sessions, conducting in- service education, displaying the protocols in labour room, post natal ward, nursery etc.

There is no data available regarding the infection arising from the lack of care immediately after the delivery, since mothers get discharged within few hours after delivery. However efforts will be taken in future researches to assess the consequences of lack of care.
Acknowledgement: We are very grateful to research and ethical committees of BPKIHS for the approval and funding of this study. We also would like to thank Mr Dharidhar Baral in statistical assistance and nursing personnal particularly Mrs Bhima Kumari Katuwal who helped in data collection. Our sincere thanks also due to Mrs Vijayalakshmi, for her support and help through out this study.

\section{References}

1. Deorari AK. Hypothermia in Newborn. Asian Journal of Obstetrics \& Gynae Practice. 1999; 3 (1): 49-51.

2. World Health Organization. 1996 World Health Statistics Annual. Geneva: World Health Organization;1998. A-5.

3. Ministry of health, His Majesty's Government. Annual report (2004/2005). Nepal: Department of health service, Ministry of health; 2006. P.17.

4. Wegman ME. Annual summary of vital statistics. Paediatrics. 1983;9(83):944-50.

5. Park K. Park's Textbook of Preventive \& Social medicine. 15th edition. Premnagar Jabalpur: Ms Banarasidas Bhanot;1997.

6. Murray SF. Neonatal care in developing countries. Mod Midwife. 1997;7(10): 26-30.

7. World Health Organization. Integrated management of pregnancy and child birth, PCPNC. 2nd edition. Geneva: World Health Organization;2006.

8. Kelly JM. General Care. In: Avery GB, Fletcher MA, MacDonald MG. Neonatology: Pathophysiology management of the Newborn. 4th edition. Philadelphia: JB Lippincott; 1994.p.301-5.

9. Enkin MW, Keirse MJNC, Renfrew M, Neilson J. Guide to effective care in pregnancy and childbirth. 2nd edition. USA: Oxford University; 1995.p.417-20.

10. Marlow DR, Redding BA. Textbook of Paediatric Nursing. 6th edition. Philadelphia: W B Sounders Company. 1998.

11. Shakya SD. Nursing care received by the postnatal mothers \& newborn babies in maternity wards of Christian Medical College \& Hospital, Vellore1999. Unpublished thesis of Master of Science in Nursing, Tamilnadu Dr. M.G. R. Medical University, Chennai, India.

12. Bennett VR, Brown LK. Myles Textbook for Midwifery. 15th edition. Churchill Livingstone: Mary Law: 2005. 
13. Pillitteri A. Maternal \& Child Health Nursing care of the childbearing \& childbearing family.4th edition. Philadelphia: J.B Lippincott; 1998.

14. Dutta DC. Textbook of obstetrics including Perinatology. 6th edition. Calcutta: New Central Book agency.2004.

15. Malar PSV. Baby friendly hospital initiative implementation in CMCH, Vellore 1999. Dissertation for Degree of Master of Science in Nursing to Tamilnadu Dr. M.G. R. Medical University Chennai, India.

16. WHO/UNICEF. The Global criteria for the WHO/UNICEF Baby Friendly Hospital Initiative. Geneva: WHO; 1992.
17. Salaria EM, Cater JI, Easton PM. Duration of breast feeding after an early initiation \& frequent feeding. Lancet. 1978;11:1141-3.

18. Awasthi S, Malik GK, Mishra PK. Mortality pattern in breast versus artificially fed term babies in early infancy. Indian Paediatrics. 1991; 28:243-7.

19. Entwistle F. Breast-feeding the most natural function. Nursing Times. 1991;87: 24-6.

20. Reeder SJ, Martin LL, Koniak D. Maternity Nursing; Family, Newborn \& Women's Health Care. 17th edition. Philadelphia; JB.Lippincott. 1992. 